\title{
¿Cómo los creativos de la publicidad generan sus ideas?
}

\author{
CÉSAR ATEHORTÚA \\ Politécnico Grancolombiano \\ catehort@poligran.edu.co
}

Publicista de la Universidad Jorge Tadeo Lozano, profesional en Mercadeo y Publicidad del Politécnico Grancolombiano, Magister en Educación en la línea de Cognición Creativa, doce años de experiencia docente y veinte años como publicista, profesor de Publicidad de la Facultad de Mercadeo, Comunicación y Artes, y coordinador académico de Publicidad del Departamento de Mercadeo y Publicidad.

Fecha de recepción: 1 de julio de 2010

Fecha de aprobación: 13 de septiembre de 2010

\section{Resumen}

Esta investigación estuvo encaminada a caracterizar los procesos cognitivos creativos presentes en publicistas expertos, a partir de una investigación exploratoria de estudio de caso.

La investigación contó con una tarea cognitiva que se aplicó a dos directores creativos, con amplia trayectoria en el mundo publicitario y a dos creativos junior, que empiezan su carrera profesional. La tarea cognitiva en esta investigación consistió en desarrollar una pieza gráfica (afiche-producto) teniendo como base un brief. Luego de recopilar la información, se hizo un análisis de la pieza publicitaria (afiche) bajo el enfoque de cognición creativa con el modelo Geneplore, el cual permitió establecer los procesos generativos, las estructuras y propiedades preinventivas, y los procesos exploratorios presentes en la creación del afiche por parte de los creativos publicitarios.

La investigación permitió corroborar que el modelo Geneplore, utilizado como instrumento de abordaje para la creatividad publicitaria, es apropiado y consistente. De acuerdo con lo anterior, se hizo evidente que la creatividad publicitaria no requiere de la participación de todos los procesos generativos, ni involucra todas las estructuras preinventivas ni de todos los procesos exploratorios, como tampoco de todos los procesos exploratorios descritos en el modelo Geneplore. Sin embargo, dada la complejidad del tema y de las limitaciones propias del diseño de la investigación, los resultados obtenidos no pueden ser generalizados y requieren ser validados por medio del estudio de una muestra poblacional más amplia.

\section{Palabras Claves}

Procesos cognitivos creativos, creatividad publicitaria, modelo Geneplore, procesos generativos, estructuras preinventivas, propiedades preinventivas, procesos exploratorios

\begin{abstract}
This research was aimed to characterize the creative cognitive processes that are present in expert publicists, from an exploratory investigation of a case study.

This research had a cognitive task that was applied to two creative directors that have an extensive professional experience in the world of advertising and to two junior creative executives that are beginning their career path. The cognitive task in this research consisted in developing a graphic piece (poster - product) having a brief as the basis. After gathering all the information, an analysis of the graphic piece (poster) was made under the creative cognition approach of the Geneplore model. This approach allowed establishing generative processes, preinventive structures and properties, and the exploratory processes that are present in the creation of the poster by the creative directors.
\end{abstract}

The research allowed corroborating that the Geneplore model used as the addressing instrument for creativity in advertising is appropriate and consistent. According to this, it was evident that creativity in xdvertising does not require the participation of every generative process and does not involve every preinventive structure or property, or every exploratory process described in the Geneplore model. However, due to the complexity of the topic and to the limitations related to the design of the research, the results obtained cannot be generalized and should be validated through the study of a wider population sample.

\section{Keywords}

Creative Cognitive Processes, Advertising Creativity, Geneplore Model, Generative Processes, Preinventive Structures, Preinventive Properties, Exploratory Processes. 


\section{Introducción}

La creatividad no es un gen que se hereda o un atributo que se posee de manera indefinida, y nadie es un sujeto creativo durante todo el tiempo, existen momentos en la vida de los individuos en los que la creatividad tiene sus puntos máximos y mínimos de producción. Para Seltzer y Bently (1999, p.13) "la creatividad no es una habilidad que pueda ejercitarse por imperativos, sino más bien una forma de interacción entre el aprendiz y su entorno. Los autores se refieren a características del entorno que consiguen fomentar la creatividad como pueden ser: la confianza, la libertad de acción, las variaciones de contextos, el equilibrio entre la capacidades y desafíos, el intercambio interactivo de conocimiento e ideas y los resultados reales.

Carlos Figueroa Navarro, en su libro Creatividad, diseño y tecnología (2000, p.1) define la creatividad como

Una característica natural de la especie humana, mediante la cual sus individuos han resuelto muchos de los problemas de su existencia, es una de las cualidades que mejor nos distinguen de las otras especies de seres vivos a tal punto de ser considerada como un acto divino.

En el libro La fuerza de la publicidad, Moliné (2000, p.373) cita una frase de Bernbach

La creatividad, ¿es una forma de arte oscura y esotérica?
Jamás. Es la cosa más práctica que un hombre puede em-
plear. $\mathbb{1}$ problema surge culando se tiene que encontrar
una ìdea creativa, el ejercicio creativo publicitario se sus-
tenta hoy en día en la experiencia de trabajo y en cierta
capacidad innata de los sujetos para generar ideas nuevas
y creativas.

Es preciso comenzar a concretar de manera científica como trabaja el proceso creativo cognitivo en la mente de los destacados creativos de agencia para apartar este ejercicio del llamado "chispazo", o "forma de arte oscura”, como se lo preguntó Bernbach a la hora de explicar la creatividad publicitaria. Es de vital importancia para los futuros publicistas creativos, conocer cuál es la caracterización de los procesos cognitivos creativos presentes en los creativos de agencia que han dado como resultado grandes ideas en sus campañas.

\section{Antecedentes}

En el diario vivir hay múltiples acciones que se hacen necesarias, una de ellas y que compete a esta investigación es la creatividad. En los diferentes campos profesionales la creatividad ejerce hoy en día gran importancia. Para el mundo publicitario la creatividad es un ingrediente muy importante para lograr éxito en la venta de productos o servicios. Moliné (2000) afirma que existe la certeza de que la creatividad publicitaria es lo que proporciona el éxito en los anuncios, esta creatividad publicitaria no ha sido estudiada desde las teorías de las ciencias cognitivas.

Luego de observar varias tesis relacionadas con los procesos cognitivos creativos, se encontró que los campos de estudio a los que se hace referencia en ellas están del lado de la arquitectura y del diseño de objetos pero no del lado de la publicidad. En la revisión hecha de artículos para esta investigación de revista indexadas como Creativity Research Journal, thinking skills and creativity y cognition. Internacional journal of cognitive science; publicados durante los últimos cinco años tampoco se encontró algún texto que tuviera como objeto de estudio el análisis de la creatividad publicitaria, desde las ciencias cognitivas.

El estudio de los procesos cognitivos creativos ha tenido gran desarrollo en las últimas décadas y existen enfoques que han ayudado a profundizar en la creatividad cognitiva como el de Margaret Boden (1994), quien afirma que la creatividad es un proceso que usa estructuras mentales y que no es propiedad de unos pocos. Boden estudia la creatividad mediante la metáfora del ordenador.

También está el enfoque propuesto por Ronald Finke, Thomas Ward y Steven Smith (1996), para quienes al igual que Boden, la creatividad no es propiedad de unos pocos y esta puede ser explicada de manera científica. Afirman también que la creatividad se genera mediante una actividad mental compuesta por una diversidad de procesos y estructuras cognitivas. Estos autores presentan el modelo Geneplore, como un medio para estudiar estos procesos y estructuras cognitivas en humanos. 
Una fundamentación teórica basada en la psicología computacional y la cognición creativa, explica cómo se presenta el proceso cognitivo creativo en los expertos de la publicidad en el desarrollo de una campaña publicitaria.

Lo anterior permitirá también obtener algunas repuestas relacionadas con la generación de ideas creativas mediante la identificación de los procesos cognitivos creativos de los publicistas expertos, esta identificación puede ser aprovechada desde la academia para establecer una guía más clara de cuáles deberán ser los aspectos cognitivos creativos que se deberán trabajar en los estudiantes, para alcanzar logros más elevados en la generación de ideas creativas.

Finalmente, los resultados de esta investigación permitirán no solo explicar cómo se produce la generación de ideas en los expertos publicistas, también ayudarán al diseño de instrumentos pedagógicos, que implementados en estrategias didácticas mejorarán el desarrollo creativo de los estudiantes de la carrera de Publicidad.

\section{Creatividad: hacia su definición y comprensión}

Muchas son las definiciones de creatividad y variados los enfoques desde donde se ha estudiado. En el diccionario de ciencias cognitivas de Houdé, Kayser, Koenig, Proust y Rastier (2003, p.115) se define la creatividad como

la capacidlad de realizar una producción a la vez novedosa y adaptadla. Esta producción puede ser una idea, una composición musical, una historia, un mensaje publicitario o cualquier otra forma de creación.

La creatividad durante muchos años ha sido asociada al misterio y en un pensamiento romántico solo atribuible a grandes artistas, es sorprendente el desarrollo creativo de Picasso o Dalí, la composición musical de Beethoven o Mozart, la producción literaria de Shakespeare o Cervantes y las teorías que han cambiado la percepción del mundo desarrolladas por hombres como: Einstein, Newton, Galileo Galilei, entre muchos otros.

Pero a pesar de que el mundo vive, y crece social, tecnológica y culturalmente sobre bases creativas, solo hasta finales del siglo XX se empieza a estudiar la creatividad desde enfoques fundamentados teóricamente en las ciencias cognitivas.

En el mundo de las ciencias cognitivas surgen algunos estudiosos que han aportado interesantes definiciones sobre la creatividad y que serán citados a continuación.

M. Csikszentmihalyi (1998, p. 23), propone la siguiente definición de creatividad,

la creatividad es un proceso por el cual dentro de la cultura resulta modificado un campo simbólico. La creatividad versa sobre canciones nuevas, ideas nulevas, máquinas nuevas.

Para Howard Gardner (1995, p 45), la creatividad es la caracterización reservada a los productos que son inicialmente considerados como novedosos en una especialidad, pero que, en último término, son reconocidos como válidos dentro de la comunidlad pertinente.

Margaret Boden (1994, p. 65), por su parte, afirma que la creatividad es: "una idea genuinamente original o creativa es una que no puede ser descrita y/o producida por el mismo conjunto de reglas que otras conocidas".

Finke, Ward y Smith, en su libro Creative Cognition (1996, p. 2), definen la creatividad como "El producto de muchos tipos de procesos mentales, cada uno de ellos contribuye a sentar las bases para la visión creativa y de descubrimiento".

Como complemento a las anteriores definiciones, es importante tener en cuenta los seis modelos propuestos por Sternbergn y Lubart en el artículo titulado "The Concept of Creativity: Prospects and Paradigms" presentado en el Handbook of Creativity (1999)

En este artículo, los autores presentan el modelo místico, que tiene como idea principal la concepción creativa como una inspiración procedente de un acto trascendental o divino.

\footnotetext{
Algunas corrientes orientales consideran la creatividad como el resulltado de un esfuerzo por alcanzar estados espirituales más altos de conciencia. Entre muchas, la propuesta por MY Maharishi ha sido una de las que mayor reconocimiento ha obtenido (Parra, Marulandla, Gómez y Espejo, 2005, p. 40).
} 
Un segundo modelo o enfoque es el psicoanalítico, la idea central propone una creatividad que emerge de la tensión entre la realidad consciente y la inconsciencia. Freud afirmaba que los artistas conciben sus obras para expresar sus deseos inconscientes de una manera públicamente aceptable. El enfoque gira alrededor de los aspectos de la personalidad y de las motivaciones de los individuos.

El tercer modelo es el paradigmático, el objetivo principal en este modelo es el de desarrollar la creatividad antes que explicarla. El mayor representante de este modelo es Edward De Bono, quien considera que

la creatividad es el resultado de un pensamiento provocador, que efectúa saltos, no sigue un patrón preestablecido y no emplea categorías fijas (pensamiento lateral) que se opone al pensamiento lineal de tipo lógico-matemático (pensamiento verticall) (Parra, Marulanda, Gómez y Espejo, 2005, p. 41).

El modelo psicométrico es el cuarto en esta lista de Sternberg, y se basa en la medición de los factores que intervienen en la creatividad. El mayor representante es Guilford. Para él, la creatividad está estrechamente relacionada con la inteligencia, y está compuesta por tres dimensiones, los contenidos, las operaciones y los productos. La interacción de estos factores da lugar a la creatividad.

Un quinto modelo es el sociopersonal, los enfoques de este modelo se desarrollan a la par con los enfoques cognitivos. Este modelo presenta gran interés por la manera en que la creatividad abarca todos los campos de la vida humana y los efectos que esta pueda tener en las transformaciones sociales.

Por último, Sternberg presenta el modelo cognitivo, cuyo motivo de investigación es el de saber cuáles son las representaciones y los procesos mentales que están presentes en la creatividad. En este modelo se encuentran los enfoques de cognición creativa de Finke, Ward y Smith (1996) y el computacional de M. Boden (1994).

Ambos enfoques consideran que la creatividad no es el fruto de un único talento o capacidad, sino que es resultado de la interacción de diversos procesos mentales que todos los individuos pueden desarrollar y refinar por medio de la experticia. En tal sentido, no estiman que la creatividad esté limitada a unos pocos elegidos (Parra, Marullanda, Gómez y Espejo, 2005, p. 41).

En el enfoque de cognición creativa los autores presentan, por medio de su modelo Geneplore, una explicación de cómo se da el acto creativo. El modelo se compone de dos fases procesales, la generativa y la exploratoria. En la fase generativa, los procesos involucrados dan origen a las representaciones mentales denominadas estructuras preinventivas; las propiedades de estas estructuras son examinadas en la fase exploratoria, con el fin de interpretarlas de manera significativa, para que de tal forma se pueda pasar a la realización de los productos finales traducidos en ideas, objetos, etcétera.

Luego está el enfoque computacional, la mayor representante de este enfoque es Margaret Boden, que propone su modelo de simulación computacional para explicar la creatividad. Para la autora, la creatividad surge de los procesos de exploración y transformación de espacios conceptuales.

Un espacio conceptual es la organización de una serie de principios que unifican y estructuran un dominio de conocimiento. Explorar un espacio conceptual es una forma específica de creatividad: es transformarlo en otro (Parra, Marulanda, Gómez y Espejo, 2005, p. 45).

En relación con lo anterior, Boden afirma "Para que se justifique llamar a una idea creativa, entonces, se deben identificar los principios generativos respecto de los cuales ésta es imposible" (Boden, 1994, p. 65). La autora aporta una novedosa forma de explicación de la creatividad al utilizar un modelo en el que se describen los espacios conceptuales que se encuentran en la mente y las formas de transformarlos. Es esta transformación de los espacios conceptuales la que da origen a la creatividad. Por medio de los sistemas generativos se originan los espacios conceptuales como las reglas, los "podría" o "no podría".

En la descripción de cómo se produce el acto creativo, Boden plantea la cartografía mental como un proceso que explora los espacios conceptuales dando como resultado los mapas mentales. Los buenos mapas mentales son los que tienen como base la experticia o el conocimiento sobre algo. 
En lo que concierne a la creatividad, los mapas en cuestión son mapas de la mente. Estos mapas de la mente, que son en sí mismos mapas en la mente, son sistemas generativos que guían el pensamiento y la acción por allgumos caminos pero no por otros (Boden 1994, p. 75).

En este proceso están implícitos los "podría” y "no podría”, es una total exploración en la mente a través de los árboles de búsqueda (recorridos en la mente para encontrar una meta).

En el recorrido para encontrar una meta surge la heurística, esta actúa como una forma de explorar los campos conceptuales con mayor probabilidad para llegar a una solución, ya que esta forma parte de los recursos computacionales de la mente.

Muchas heurísticas dan por supuesto el mapa actual del espacio conceptual, dirigiendo al pensador por este camino y no por aquél. Otras cambian el mapa, superficialmente o no, de modo que puedan abrirse nuevos caminos que no estaban disponibles con anterioridad (Boden 1994, p. 83).

Las heurísticas pueden ser de carácter específico a un dominio, otras son de carácter general, como puede ser considerar la negación como fórmula para obtener un nuevo enfoque a la hora de resolver un problema, o eliminar restricciones para lograr la meta. El resultado de la aplicación de las anteriores reglas puede generar el cambio en la cartografía mental.

Muchos de los cambios conceptuales son tan fuertes que los expertos en dominios específicos necesitan hacer un gran esfuerzo para aceptar ese cambio radical presentado por un creador.

En el modelo computacional es importante entender, como lo dice (Boden 1994, p. 122), que " $[\cdots]$ existen reglas y restricciones, la creatividad se hace posible cuando existen reglas y restricciones al pensamiento" En muchos ejercicios académicos es común encontrar que se da total libertad para la creación lo que genera al final solo confusión, las limitantes ayudan a fortalecer el árbol de búsqueda para encontrar el mejor de los caminos a una solución.

En el campo de las ciencias cognitivas, se encuentra otro modelo que busca explicar cómo funciona la creatividad, y es el modelo Geneplore de Finker, Ward y Smith. En el enfoque propuesto por estos tres autores, se considera la creatividad como un aspecto potencial que poseen todos los seres humanos, y que se puede presentar en diferentes campos del conocimiento.

El modelo Geneplore se sustenta sobre dos bases fundamentales: la generativa y la exploratoria. En la fase generativa se construyen representaciones mentales llamadas estructuras preinventivas, que son el resultado de una serie de procesos generativos particulares. Estas estructuras preinventivas son evaluadas en una segunda fase denominada exploratoria, en la cual es valorada la efectividad de sus propiedades para la resolución de la tarea. El refinamiento de las estructuras preinventivas, se da en una interacción constante entre la fase generativa y la exploratoria, siempre teniendo en cuenta las restricciones de la tarea dada. Las restricciones y su especificidad son las que incrementan el surgimiento de estructuras más creativas, es decir, que a mayor cantidad de restricciones, mayor será la exigencia del producto creativo.

En la Figura 1 se aprecia el esquema del ciclo proceso creativo:

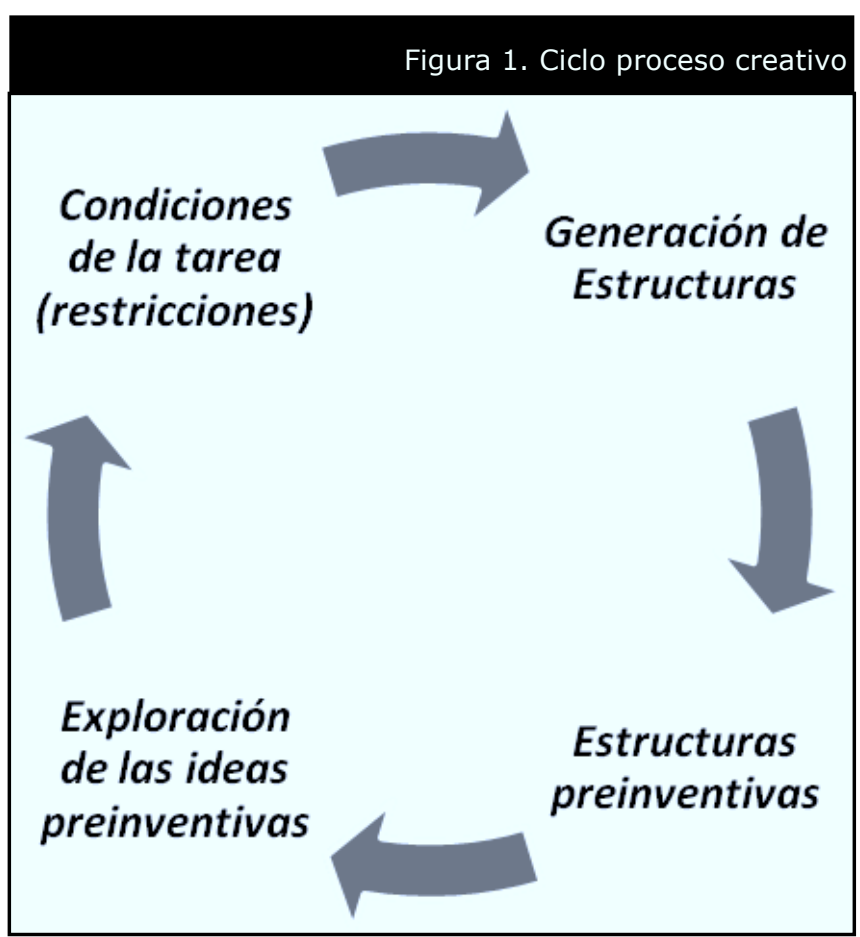


Es claro mediante estas teorías sí se puede estudiar con más fundamento el proceso creativo de los seres humanos. Existen conexiones claras entre los procesos mentales y el entorno, entre la capacidad de generar nuevas ideas y las estructuras mentales que las originan.

\subsection{Procesos generativos}

- Recuperación o recuerdo: consiste en la recuperación de las estructuras existentes de la memoria y la formación de asociaciones entre estas estructuras.

- Asociación: formación de asociaciones entre estructuras existentes en la memoria. Está relacionada con la agrupación de señales, características o parámetros que corresponden a un mismo conjunto y que por tanto comparten algún grado de similitud (Finke, Ward y Smith, 1996, p.20)

- Síntesis mental: es un proceso a través del cual se ensamblan partes que pueden conformar un todo; requiere de la transformación mental para reorganizarlas, logrando rotar las imágenes así como cambiarlas de tamaño, doblarlas, distorsionarlas o imprimirles movimiento.

- Transformación mental: imágenes mentales transformadas. Conceptos que pueden ser relacionados con otros para general conceptos más complejos, alterando el significado inicial de los conceptos.

- Transferencia analógica: se refiere a una relación o un conjunto relaciones que de un contexto, se transfiere a otro, resultado una estructura preinventiva que es análoga y familiar. Hace alusión a la transferencia de parte del conocimiento de un dominio ya conocido (dominio fuente) a un dominio nuevo (dominio objetivo).

- Reducción categorial: reducir mentalmente objetos o elementos a la más primitiva categoría de descripción. (Finke, R., Ward, T., y Smith, S. 1996, p.20).

\subsection{Estructuras preinventivas}

- Patrones visuales y formas de objetos: estas estructuras generalmente toman forma de imágenes visuales y espaciales.

- Mezclas mentales: clase de estructuras que incluye combinaciones mentales, metáforas e imágenes mentales combinadas. Lo que tienen en común es que dos entidades distintas han sido fusionadas para crear algo nuevo.

- Categorías inusuales: ejemplificaciones de categorías inusuales o hipotéticas que tienen características comunes a las categorías familiares y características novedosas emergentes que conducen a descubrimientos nuevos e inesperados.

- Modelos mentales: son estructuras preinventivas a gran escala que representan sistemas físicos y mecánicos. Usualmente comienzan como estructuras incompletas, inestables e incluso no científicas y luego son mejoradas y refinadas con la posterior exploración y descubrimiento.

- Combinaciones verbales: son las relaciones sugestivas e interesantes entre palabras y frases que pueden llevar a exploraciones poéticas y literarias. Difieren de las mezclas mentales en que sus elementos no necesitan ser fusionados física o conceptualmente en la estructura.

\subsection{Propiedades preinventivas}

- Novedad: una estructura familiar puede ser interpretada en formas creativas. La posibilidad para un descubrimiento creativo debe ser mayor si la estructura no es relativamente común al comienzo.

- Ambigüedad: la ambigüedad contribuye con descubrimientos de muchos tipos de combinaciones conceptuales. No se deben imponer interpretaciones estrechas de las estructuras preinventivas cuando las estructuras se están formando al comienzo.

- Significación: sentido percibido y general del 
"significado" en la estructura. Este sentido del significado puede ser más o menos abstracto y está relacionado con el potencial de la estructura preinventiva para inspirar interpretaciones nuevas e inesperadas.

- Emergencia: se refiere a las características y relaciones inesperadas que aparecen en la estructura preinventiva.

- Incongruencia:se refiere al conflicto o contraste entre elementos en una estructura preinventiva. Esto usualmente lleva a una exploración posterior para descubrir significados más profundos y relaciones que permitan conciliar el conflicto y reducir la tensión psicológica que este crea.

- Divergencia: se refiere a la capacidad para encontrar múltiples usos o significados en la misma estructura.

\subsection{Procesos exploratorios}

Encuentro de atributos: la búsqueda sistemática de características emergentes en las estructuras preinventivas. Puede ser usado para encontrar características emergentes resultantes de la creación de combinaciones conceptuales y de metáforas.

Interpretación conceptual: se refiere al proceso de tomar una estructura preinventiva y encontrar una interpretación abstracta, metafórica o teórica de ésta.

Inferencia funcional: exploración de los usos potenciales o funciones de una estructura preinventiva (este proceso se facilita al imaginarse a sí mismo usando un objetivo de diferentes maneras).

Cambio contextual: Considerar una estructura preinventiva en nuevos o diferentes contextos, como una forma de obtener insights sobre otros usos o significados posibles de la estructura.

Evaluación de hipótesis: cuando se busca interpretar las estructuras como posibles soluciones a un problema, se pueden generar estructuras preinventivas, que representen varias posibilidades de solución y luego explorar las implicaciones de esas estructuras para solucionar el problema.
Búsqueda de limitaciones: las estructuras preinventivas pueden proveer de insights sobre ideas o soluciones que no funcionen. Descubrir las limitaciones puede ayudar a restringir búsquedas futuras y a enfocar la exploración creativa en direcciones más promisorias.

\section{Método}

Esta investigación fue un estudio de caso de tipo exploratoria con un diseño no experimental transeccional descriptivo (Hernández, Fernández y Baptista, 1991) que fue llevada a cabo mediante la aplicación de una tarea cognitiva enfocada a identificar los procesos cognitivos creativos que subyacen a la producción de piezas publicitarias.

En este sentido, el diseño está planteado en torno a la descripción de la creatividad en la publicidad, en su aspecto externo y en su estructura interna, sobre la base de una teoría que explica la creatividad y de sus relaciones con la producción creativa publicitaria (Bermejo, 2003).

Para el desarrollo de la tarea cognitiva la población seleccionada fueron dos directores creativos (Calvache y Cañas) con amplia trayectoria y alto rendimiento en la producción de campañas creativas reconocidas en el campo publicitario colombiano, y dos creativos junior (Gómez y Patiño), cuya selección se logró gracias a las recomendaciones de expertos de diferentes agencias de publicidad reconocidas de Bogotá. Para la realización de la prueba los directores creativos y los creativos junior fueron citados al mismo tiempo en un solo lugar.

La tarea consistía en desarrollar una pieza gráfica (afiche-producto) teniendo como base un brief. Este contenía la información necesaria para el desarrollo de la tarea como los antecedentes, los objetivos que se debían cumplir al crear el producto, el posicionamiento que se esperaba, el grupo objetivo al que se quería llegar con el mensaje, el tipo de pieza publicitaria que se requería, y una breve información de tres de las ciudades más importantes de Latinoamérica como: Sao Pablo, Buenos Aires y Santiago de Chile.

Para esta tarea los sujetos solo podían contar con hojas de papel bond, lápiz o colores, y un tiempo máximo de dos horas para cumplirla. Los sujetos se reunieron en un mismo lugar y el desarrollo de la tarea fue al mismo tiempo para todos. 
En esta investigación se utilizaron tres tipos de instrumentos: uno para el desarrollo del proceso de construcción del producto publicitario y dos para el análisis. El primero se refiere al formato entregado al sujeto con las instrucciones para la elaboración de una pieza publicitaria (brief), el segundo, correspondiente a las matriz elaborada por el investigador para el registro, la sistematización y el análisis de la información. La matriz referida fue estructurada en torno a los dos elementos fundamentales del proyecto: la creatividad y la creatividad publicitaria. Se definieron las siguientes categorías: procesos generativos, estructuras preinventivas, propiedades preinventivas y procesos exploratorios. Y la última matriz se construyó tomando como referencia la fórmula de la creatividad de Marcal Moliné, que contiene los conceptos de incertidumbre, inferencia y descubrimiento. La incertidumbre: cuando lo que dice el anuncio, no acaba de encajar en lo que las personas saben de la vida.

- Las inferencias: lo que se dice es lo que el consumidor trata de averiguar, a partir de lo que se ha dicho y que le ha causado incertidumbre. El creativo ha pensado en el anuncio, de modo que la incertidumbre tenga la fuerza suficiente como para despertar interés en lanzar inferencias y que, como consecuencia de ese esfuerzo intelectual, el lector llegue a descubrir lo que este quiere decir.

Buscar en los archivos de la mente, algo que explique el interrogante de la incertidumbre.

- El descubrimiento: comprender, después del anterior esfuerzo intelectual, qué es lo que el creativo en el mensaje del anuncio quiere contar.

\section{Análisis de resultados}

Los directores creativos (Calvache y Cañas) fueron seleccionados por su trayectoria y alto rendimiento en la producción de campañas creativas reconocidas en el campo publicitario colombiano, en cuanto a los creativos junior (Gómez y Patiño) la selección se logró gracias a las recomendaciones de otros expertos de la publicidad que trabajan con ellos en una reconocida agencia de Bogotá. Para la realización de la prueba los directores creativos y los creativos junior fueron citados al mismo tiempo en un solo lugar.

De las dos horas de tiempo máximo para el desarrollo de la tarea, los directores creativos necesitaron solo de una hora y treinta minutos aproximadamente. El alto grado de experticia permitió a los directores creativos lograr la tarea en este tiempo. M. Boden afirma que ser creativo implica ser experto en uno o varios campos disciplinarios.

Los creativos junior lograron la tarea en dos horas exactamente. Los junior necesitaron más tiempo para desarrollar la tarea al de los directores creativos, debido al poco grado de experticia que aún poseen.

En la creación del afiche o producto final, los directores creativos fueron más creativos que los junior al desarrollar la pieza, porque lograron generar: incertidumbre, inferencia y descubrimiento. La fórmula de la creatividad propuesta por Moliné fue clara en los dos directores creativos.

En la composición de la pieza (imagen y copy) se logró seleccionar el target o grupo objetivo, por ambos grupos. La imagen que creo Calvache fue asociada a la torta de negocios, imagen común en una presentación de gerencia. El texto propuesto por el mismo sujeto estuvo dirigido a los hombres de negocios que buscan nuevas mercados, "Bogotá una ciudad en donde siempre nos llevamos una participación en los negocios" (texto de la pieza). La torta de negocios, no es una imagen que encaje directamente con lo que podría ser un anunció de Bogotá. Además, en los pedazos de la torta hay una imagen de un corazón que ayuda a reforzar la incertidumbre de la pieza.

Al continuar con el análisis del afiche de Calvache se encuentra una torta de negocios que se expone en una conferencia. La torta se subdivide en cuatro partes, cada una de ellas relacionadas con una palabra, y una de las cuatro partes se convierte en un corazón lo que hace que el receptor deba recurrir a sus conocimientos previos en un intento por comprender la información. Por último después del anterior ejercicio intelectual, el lector del anunció comprende que se trata de una forma interesante y creativa de mostrar las ventajas que tiene Bogotá como capital de Suramérica. En este mensaje el texto que complementa la imagen aclara 
todo "Bogotá, una ciudad donde siempre nos llevamos una participación en los negocios", seleccionando así el target. La propuesta de Calvache rompe con la regla de mostrar los lugares más atractivos de Bogotá por medio de fotografías espectaculares o de estadísticas sobre la ciudad como argumento para promocionarla, y propone una nueva imagen por medio de una figura familiar para los hombres de negocios invitándolos a descubrir el objetivo del mensaje.

Cañas, segundo director creativo que participó en la investigación, propuso una imagen que parte de la ubicación geográfica de Colombia dentro de Suramérica y que contiene todos los íconos representativos de las más importantes ciudades de Latinoamérica, acompañó esta imagen con un texto que estuvo dirigido a las personas que buscan nuevos lugares para hacer turismo, "Bogotá, el único lugar donde toda Latinoamérica quisiera estar".

La imagen del afiche de Cañas muestra una gran cantidad de figuras, que son íconos reconocidos de las grandes ciudades de Suramérica. Toda ellas ubicadas en la parte superior de América del Sur. Esta imagen no corresponde con la acostumbrada sobre esa zona geográfica, generando incertidumbre pero en menor grado que el logrado por el afiche de Calvache, la solución lógicamente aceptable de la imagen principal se encuentra más rápidamente.

En la parte superior de la pieza, y sobre la imagen de Suramérica emergen figuras que hacen alusión a ciertos lugares característicos de algunas ciudades de Suramérica. Todas las imágenes salen unidas unas a otras. De acuerdo con lo anterior las inferencias son más sencillas en su elaboración, el posible o posibles significados de la información se encuentran de manera más rápida, lo que hace que el receptor, no tenga sorpresa al descubrir que el mensaje invita a los turistas a visitar a Bogotá por tener todas las ventajas que tienen las principales ciudades de Latinoamérica. Después de hacer la lectura total y de haber hecho su ejercicio intelectual, el lector descubre que se trata de todos los íconos de Suramérica que emergen de Colombia y en especial de Bogotá. Cañas cierra el mensaje con el siguiente copy "Bogotá, el único lugar donde toda Latinoamérica quisiera estar" cumpliendo también, como lo hizo Calvache, al escoger entre los dos grupos objetivos al turista, dando cuenta así con una importante restricción de la tarea.
Este análisis se logró después de una detallada aplicación del modelo Geneplore, sobre la base del significado de los procesos generativos y exploratorios, y de las estructuras y propiedades preinventivas.

\subsection{Por procesos generativos}

Con relación a los procesos generativos fue la reducción categorial el más particular, solo se presentó en los directores creativos. Calvache partió su análisis desde el concepto de capital, que le permitió desde una panorámica más amplia para establecer las diferencias entre una ciudad común y una gran ciudad capital, y Cañas lo hizo desde el concepto de "Pangea", relacionada esta como un único y gran lugar en el que convergen múltiples elementos. Esta reducción categorial demuestra la claridad de los espacios conceptuales y en el árbol de búsqueda que poseen los directores creativos, comparados con los creativos junior que no lo hicieron.

La transferencia analógica la hizo Calvache al llevar el concepto de torta de negocios a lo que significa Bogotá como ciudad para invertir, y Cañas lo hizo al ubicar todos los íconos de las ciudades más importantes de Latinoamérica dentro de Colombia. Finalmente, el último proceso generativo representativo en los dos directores creativos fue la síntesis mental, Calvache integró varios elementos que componen una torta de negocios con las ventajas que se obtienen al invertir en Bogotá, creando así una nueva estructura, y Cañas reunió todos los íconos de las ciudades más importantes de Latinoamérica en un único lugar, Colombia. También aparecieron en todos los sujetos de la investigación, la transformación mental, el recuerdo y la asociación, estos dos últimos necesarios para crear.

\subsection{Por estructuras preinventivas}

Con respecto a las estructuras preinventivas fue la categoría inusual la que marcó la diferencia al presentarse solo en los directores creativos. Calvache lo logró por medio de asociar a Bogotá con una torta de negocios, en la que una de sus subdivisiones contiene un corazón. Y Cañas, la encontró creando una nueva imagen de Bogotá con todos los íconos de las ciudades más importantes de Suramérica. Las mezclas mentales en Calvache surgieron al lograr en su propuesta la imagen de una torta de negocios con un corazón y 
esta con los beneficios que representa la inversión en Bogotá, Cañas lo hizo al fusionar todos los íconos de las principales ciudades de Suramérica en Bogotá; Gómez mezcló el concepto de centro o eje con Bogotá como centro del mundo, este creativo junior creó el afiche solo con texto. En Patiño, la mezcla mental surgió al superponer las imágenes de la torre Eiffel, en París, con la torre Colpatria en Bogotá. La combinación verbal se presentó en todas las propuestas, cabe anotar que esta última, en el desarrollo de todas las piezas publicitarias es importante porque es el copy el que concreta el mensaje. No se presentaron los modelos mentales.

\subsection{Por propiedades preinventivas}

La novedad, la ambigüedad, la significación, la emergencia, la incongruencia y la divergencia se presentaron entre los dos directores creativos y solo en uno de los creativos junior. En las propiedades preinventivas se ve reflejada la propuesta creativa de los sujetos de la investigación, estos crearon imágenes y textos que cumplen con la fórmula de la creatividad de Moliné por medio de la incertidumbre, las inferencias y el descubrimiento.

La novedad en la propuesta de Calvache se presenta por patrón visual y categoría inusual al diseñar una torta de negocios en la que una porción tiene forma de corazón, conduciendo a un descubrimiento nuevo e inesperado entre la imagen más común de torta de negocios y un corazón. La ambigüedad en el afiche de Calvache está del lado del patrón visual al relacionar una torta de negocios con Bogotá. Estas imágenes no son compatibles conceptualmente y por tal motivo logran generar incertidumbre.

En cuanto a la significación es claro el valor comunicativo que persigue el patrón visual, al indicar que el mensaje está dirigido a un target específico, hombres de negocios, la imagen central es una torta de negocios que ratifica el target. Esta torta de negocios se compone de una serie de porciones acompañadas de un texto, una de estas porciones rompe con el esquema tradicional al tener forma de corazón, imagen que apela a la emoción al significar que la ciudad tiene sentimiento. En este punto el lector formula inferencias para encontrar el significado de la información.
Finalmente la emergencia, la incongruencia y la divergencia proporcionan las pistas para decodificar plenamente el mensaje del afiche, reduciendo la tensión psicológica entre las imágenes del afiche y el texto. El lector de la pieza comprende que Bogotá es el mejor lugar para hacer inversiones, pero por encima de lo económico está el amor que se recibe y se da en Bogotá. Esta lectura final de comprensión del mensaje es el descubrimiento de la fórmula de Moliné.

En Cañas, la novedad se presenta por patrón visual y categoría inusual al crear una imagen en donde todos los íconos de las más importantes ciudades de Suramérica aparecen unidos y emergiendo de la zona geográfica en dónde se encuentra Colombia, aquí una estructura familiar (los íconos) es interpretada en forma creativa, conduciendo a un descubrimiento nuevo e inesperado entre los iconos suramericanos y su ubicación en el mapa. La ambigüedad en el afiche de Cañas está del lado del patrón visual al relacionar los iconos representativos de las principales ciudades de Suramérica con la ubicación geográfica que tiene Colombia. Estas imágenes no son compatibles conceptualmente y por tal motivo logran generar incertidumbre.

En cuanto a la significaciónes claro el valor comunicativo que persigue el patrón visual, al indicar que el mensaje está dirigido a un target específico, turistas, hombres y mujeres que buscan viajar por Suramérica. La imagen central del afiche está compuesta por los íconos representativos de Sao Paulo, Buenos Aires y Santiago de Chile reunidos en un mismo diseño y ubicados en Colombia, esta composición deja claro que se trata de lugares reconocidos de Suramérica y que están en Colombia. En este punto el lector formula inferencias para encontrar el significado de la información.

Finalmente la emergencia, la incongruencia y la divergencia proporcionan las pistas para decodificar plenamente el mensaje del afiche, reduciendo la tensión psicológica entre las imágenes del afiche y el texto. El lector de la pieza comprende que Bogotá es la mejor ciudad para visitar y que posee todos los atractivos de las principales ciudades de Suramérica, logrando así el descubrimiento.

En la propuesta de Patiño, uno de los creativos junior, se presentan las seis propiedades preinventivas. 
La novedad en el afiche de Patiño se exterioriza por patrón visual y categoría inusual al utilizar estructuras familiares, fusionadas entre sí, para generar una estructura nueva en forma creativa, conduciendo a un descubrimiento nuevo e inesperado entre la imagen de la torre Eiffel y la torre Colpatria. La ambigüedad en el afiche de Patiño está del lado del patrón visual al yuxtaponer la torre Eiffel y la torre Colpatria. Estas imágenes no son compatibles conceptualmente y por tal motivo logran generar incertidumbre.

En cuanto a la significación es claro el valor comunicativo que persigue el patrón visual, al indicar que el mensaje está dirigido a un target específico, los turistas, la imagen central es la torre Eiffel y la torre Colpatria conocidas por los turistas ratificando así el target. En este punto el lector formula inferencias para encontrar el significado de la información. La emergencia, la incongruencia y la divergencia proporcionan las pistas para decodificar plenamente el mensaje del afiche, reduciendo la tensión psicológica entre las imágenes del afiche y el texto.

El lector de la pieza comprende que el personaje del afiche, que se encuentra en París, está comparando una foto que tiene en sus manos de la torre Colpatria con la torre Eiffel. El copy que cierra el afiche dice "Bogotá ahora es más atractiva para el mundo". Esta lectura final de comprensión del mensaje es el descubrimiento, último paso de la fórmula de Moliné.

\subsection{Por procesos exploratorios}

En los procesos exploratorios se presentaron cinco de las seis subdivisiones: evaluación de hipótesis, interpretación conceptual, encuentro de atributos, cambio contextual, búsqueda de limitaciones. Por ser el cambio contextual el más particular al presentarse solo en los dos directores creativos y en uno de los creativos junior, estuvo reflejado por el patrón visual. Calvache lo hizo al diseñar una imagen de una torta de negocios para promocionar a Bogotá como una ciudad para invertir y ganar en corazón, en cuanto a la evaluación de hipótesis Calvache exploró con los conceptos de "capital' y "Bogotá Atenas suramericana" pensó en íconos de Bogotá como: Colpatria, plaza de toros, cerros orientales, Monserrate. También estableció relaciones entre Pan de Azúcar y Monserrate, Big Ben y Colpatria, y la torre Eiffel en los cerros orientales.
Cañas, por su parte, logró el cambio contextualubicando los íconos de las principales ciudades de Suramérica en Colombia. La evaluación de hipótesis en el caso de Cañas comenzó con el concepto de "Pangea" suramericana y continuo mediante los conceptos de: "puerta financiera de Suramérica" "misma historia, misma sangre, misma capital" y pensó en lo que tiene Bogotá diferente frente a otras capitales de Suramérica. Patiño logró el cambio contextual al proponer la torre Colpatria, de Bogotá, como un ícono de mayor importancia para el turismo frente a la reconocida torre Eiffel en París. En la evaluación de hipótesis Patiño exploró con el concepto de "ciudad de todos".

Por otro lado, Gómez desarrolló los siguientes procesos evaluación de hipótesis, interpretación conceptual, encuentro de atributos, búsqueda de limitaciones. En evaluación de hipótesis exploró por medio de la gastronomía en Bogotá, con el arte en Bogotá, y con el concepto de "También el centro de todo está aquí". Hizo un interpretación abstracta entre el concepto de capital y el de eje o centro de todo, logrando así la interpretación conceptual. La búsqueda de limitaciones para todos los sujetos de la investigación, estuvo guiada por las restricciones especificadas en el brief.

\section{Discusión}

Este trabajo puede dar paso a una investigación de mayor envergadura, que involucre a más sujetos creativos de agencia; con el fin de lograr precisar, gracias a la experticia de los creativos, cuáles son los procesos cognitivos que con mayor frecuencia emplean. Esta nueva investigación ayudaría a precisar, por ejemplo, si la reducción de categorías, es un elemento diferenciador y de gran relevancia para un gran número de creativos expertos o no.

El estudio más amplio puede ayudar a diseñar una práctica docente apropiada para lograr que los estudiantes de Publicidad y Artes mejoren la producción de material publicitario. Todo lo anterior por medio de los modelos de M. Boden y Geneplore. Al conocer cuáles son los procesos o estructuras que más evidencian los creativos expertos, se puede pensar en una práctica docente que por medio de una mediación basada en el modelo Geneplore logre afinar el proceso creativo de los estudiantes. 
La presente investigación dio paso a la creación de un conversatorio entre docentes, pertenecientes a una institución universitaria, cuya área de enseñanza tiene que ver con el tema de la creatividad; este conversatorio generó, a su vez, el interés de los participantes por profundizar en el estudio de los aportes que las ciencias cognitivas han realizado al tema en cuestión.

\section{Bibliografía}

1. Arens, W. (2000). La publicidad (7a edición). México: McGraw-Hill.

2. Prieto, M. D.; López, P.; Ferrándiz, C.; Bermejo, M. R. (2003).Adaptación de la prueba figurativa del Test de Pensamiento Creativo de Torrance en una muestra de los primeros niveles educativos.

3. Boden, M. (1994). La mente creativa. Barcelona: Gedisa.

4. Csikszentmihalyi, M. (1996). Creatividad (1a edición). Barcelona: Paidós.

5. De Bono, E. (2008). Creatividad (3a edición). Barcelona: Paidós.

6. Figueroa Navarro, C. (2000). Creatividad, diseño y tecnología (1 ${ }^{a}$ edición). Sonora: Plaza y Valdés.

7. Finke, R.;Ward, T.;Smith, S. (1996). Creative Cognition. Estados Unidos: Massachusetts Technological Institute.

8. Howard Gardner (1995, p 45) Inteligencias múltiples. La teoría en la práctica. Barcelona: Paidós.

9. Harrington, J., Hoffherr, G., Reid, R. (2000). Herramientas para la creatividad (1 ${ }^{\text {a }}$ edición). Santafé de Bogotá: McGraw-Hill.

10. Henri, J. (1996). La creación publicitaria desde la estrategia de marketing (2a edición). Bilbao: Deustos.

11. Hernández, R.; Fernández, C.; Baptista, P. (1991) Metodología de la investigación. México DF: McGraw-Hill.

12. Houdé, O.; Kayser, D.; Koenig, O.; Proust, J.; Rastier, F. (2003). Diccionario de las ciencias cognitivas (1 ${ }^{\text {a }}$ edición). Buenos Aires: Amorrortu.
13. Molina, J., Morán, A. (2008) Viva la publicidad viva (4a edición). Bogotá: Lee Lemoine.

14. Moliné, M. (2000). La fuerza de la publicidad (1 ${ }^{\mathrm{a}}$ edición). Madrid: McGraw-Hill.

15. O'Guinn, T., Allen, C., Semenik, R. (2003). Publicidad (3a edición). México: Thomson.

16. Parra, J.; Marulanda, E.; Gómez, F.; Espejo, V. (2005). Tendencias de estudio en cognición, creatividad y aprendizaje (1 $1^{\text {a }}$ edición). Bogotá: Javegraf.

17. Seltzer y Bently (1999, p.13). La era de la creatividad. México D.F. :Santillana.

18. Sternbergn y Lubart. (1999). The Concept of Creativity: Prospects and Paradigms. En Handbook of Creativity. Cambridge: Cambridge University Press.

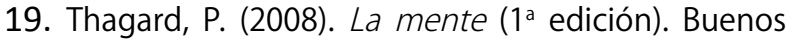
Aires: Katz. 